[Manson, H. (1992). Introduction. New Zealand Annual Review of Education, 1, ii]

\title{
HUGO MANSON
}

$\mathrm{O}$

ur aim in this publication has been to produce within one volume a central reference point for the calendar year 1991. Within this broad aim the publication serves two functions: firstly, to present the year 1991 as perceived by a number of specialists in a selection of fields of education which featured prominently during the year; secondly, to provide a comprehensive source of references which will serve as a primary port of call for researchers seeking dates, names and sign posts to further information. The articles in the first section focus on separate yet overlapping fields of education. They have in common that they all deal with a year few would dispute was one of the most tumultuous and confusing in our educational history. The entries in the second section constitute a definition in detail of that extraordinary year.

We will welcome observations on this first edition as well as suggestions and requests for inclusion in the next. 